\title{
La ciencia en contextos periféricos: producción y uso social del conocimiento científico en América Latina
}

\author{
Science in peripheral contexts: the production and \\ use of scientific knowledge in Latin America
}

\author{
Fernando Herrera García \\ 'Escuela Politecnica Nacional. \\ Quito - Pichincha - Ecuador \\ orcid.org/0000-0002-3871-811X \\ edwin.herrera@epn.edu.ec
}

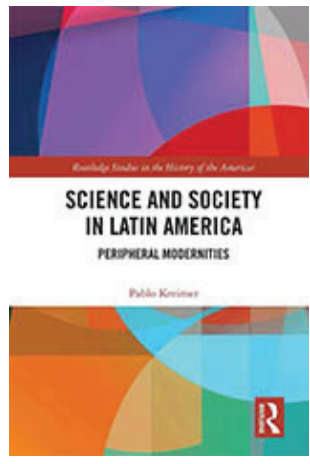

KREIMER, Pablo. Science and society in Latin America: peripheral modernities. New York: Taylor \& Francis. 2019. $270 \mathrm{p}$.
La preocupación central de Science and society in Latin America: peripheral modernities, el último libro de Pablo Kreimer (2019), es el estudio de las particularidades de los procesos de producción y uso del conocimiento científico y tecnológico en América Latina como región periférica. El texto es una síntesis, una rendición de cuentas, de 25 años de investigación en el campo de la sociología política e histórica de la ciencia.

Primero, el autor comparte confesiones y anécdotas personales como acertada excusa para pasar revista, en América Latina, a algunos de los tópicos más importantes de los estudios sociales de la ciencia y la tecnología - o campo Ciencia, Tecnología y Sociedad (CTS). A partir de su encuentro con Jean-Jacques Salomon, su director de tesis doctoral y un cómplice en sus preocupaciones políticas, estudia el rol de las políticas de ciencia y tecnología (PCT) en el desarrollo de la región. Lo también anecdótico es que para muchos de los recién llegados al campo CTS en América Latina las preocupaciones políticas y el estudio de las PCT han sido un punto de paso obligatorio o una suerte de rito de iniciación. Luego, bajo la inspiración de Latour y Woolgar (1979), inicia un segundo gran momento de trabajo. El autor pasó por varios laboratorios de biología molecular de Francia, Londres y Argentina para observar cómo los científicos producen conocimiento. Es decir, para trabajar "a lo Latour". Años después llega a un tercer encuentro crucial. Kreimer, bajo la inspiración de Hebe Vessuri, pionera del campo CTS en la región, inicia sus investigaciones sobre ciencia periférica.

En segundo lugar, el autor presenta una recopilación y selección de trabajos académicos que nos interrogan a todos, pues reflexiona sobre el rol de la ciencia en América Latina. Para ello aborda tres líneas de investigación: (1) la producción y uso del conocimiento desde una perspectiva histórica y sociológica; (2) la producción recíproca de problemas públicos 
y problemas científicos; y (3) las relaciones asimétricas entre centros y periferias en la investigación científica, quedando clara la paradoja que caracteriza la ciencia latinoamericana, o al menos la de los países más grandes de la región, el ser modernos y periféricos a la vez. En el mismo campo CTS, por ejemplo, la modernidad periférica se expresa por la dominación conceptual, metafísica e institucional del mundo angloparlante; o por el hecho de que los estudios CTS de los países periféricos, a diferencia de aquellos del mundo desarrollado, deben justificar su carácter local y subalterno y su relevancia en el mundo CTS global.

Dentro del análisis de la producción y uso del conocimiento se cuestiona si los conceptos y modos de análisis de los centros pueden usarse en las periferias y, con ello, qué clase de producción teórica es necesaria. La invitación es a repensar la organización del conocimiento científico, su producción y transferencia, así como los procesos de transmisión de estos conocimientos y la formación de las nuevas generaciones al interior de las universidades. En nuestras universidades, generalmente, estos procesos siguen una lógica disciplinar, naturalizada como la "forma correcta". Sin embargo, los problemas del mundo natural y del mundo social requieren enfoques más complejos desde una comprensión multicausal y un abordaje interdisciplinario. Es decir, a la hora de organizar la ciencia latinoamericana, a la hora de pensar en nuevos campos de investigación, o nueva oferta académica, es necesario considerar la variable de la utilidad social del conocimiento. Solo así podremos superar la paradoja de producir conocimiento que no encuentra aplicación o uso social en nuestro contexto.

Para investigar la producción recíproca de problemas públicos y problemas científicos, el autor eligió a la enfermedad de Chagas como una suerte de "organismo modelo". A través de esta enfermedad, muestra la forma en que el conocimiento científico contribuye a construir los problemas públicos. Cada aproximación, cada campo disciplinario y cada enfoque construye un objeto epistémico y un objeto de intervención social. Además, el modo de construcción del problema social determina los modos de intervención sobre el problema. Es decir, la flexibilidad interpretativa sobre Chagas muestra cómo diversos actores definen de forma diversa el problema y, consecuentemente, intervienen de forma distinta sobre el. Chagas pasó de ser un problema del campo de la medicina enfocada en descubrir los efectos del parásito sobre los enfermos, a un problema social de epidemiología y erradicación de la vinchuca como vector de la enfermedad, para finalmente ser un objeto de indagación científica en el campo de la biología molecular centrado en el estudio del parásito y las vacunas.

Por otro lado, se evidencia que la utilidad efectiva de los conocimientos para la resolución del problema social ha sido escasa. Entre los científicos que han investigado Chagas predomina una lógica de colaboración internacional y de integración con los laboratorios del mainstream de la ciencia internacional, más que una real orientación hacia la búsqueda de tratamientos de la enfermedad, fenómeno que refleja la famosa noción de integración subordinada propuesta por Kreimer. Esto se traduce en agendas locales de investigación alineadas con problemas y objetos que otorgan mayor visibilidad y legitimación científica internacional, más que con el desarrollo de productos destinados a dar respuesta a problemas locales. Ello, en este caso, se refleja en una importante cantidad de publicaciones y reconocimiento internacional y en nulo o escaso desarrollo de medicamentos y otros aportes para la lucha contra la enfermedad. 
Se muestran también las relaciones asimétricas entre centros y periferias mediante el análisis del proceso de internacionalización de la ciencia latinoamericana. El autor se pregunta ¿cómo está evolucionando la dinámica de la ciencia en las sociedades periféricas (América Latina), frente a los fuertes cambios en los sistemas de financiamiento, en la organización del trabajo científico y en el uso de nuevas tecnologías de información y comunicación? Para ello, hace un recorrido desde las ciencias coloniales, la creación de las ciencias nacionales, pasando por lo que él llama internacionalización liberal, hasta la actualidad. Plantea que los científicos latinoamericanos afrontan una nueva forma de división internacional del trabajo al integrarse a megaredes de investigación. Es decir, un gran cambio de escala en el tipo y naturaleza de las investigaciones, donde los grados de libertad en la definición de agendas de los grupos en la periferia son más reducidos y la capacidad de negociación es más limitada.

En definitiva, este libro nos convoca a la tarea de la investigación CTS comprometida, como históricamente ha sido y como la sociedad más desigual del planeta, América Latina, lo requiere. Nos plantea mirarnos al espejo y preguntarnos los por qué y para qué del trabajo científico, y los por qué y para qué del campo CTS. Ilumina problemas actuales y posibles agendas de investigación en relación con la producción del conocimiento y, sobre todo, con su uso social. Nos deja inquietudes sobre las formas en que estructuramos el trabajo científico y sobre las formas más pertinentes de evaluarlo. Retomado a Oscar Varsavsky, se pregunta si las agendas científicas de nuestros países son impuestas por los centros internacionales de poder y pone en tela de juicio el sistema de evaluación de la calidad científica que sacraliza el paper científico. Estos temas son urgentes en un contexto donde otra vez, como en décadas pasadas, los gobiernos recortan los presupuestos para la ciencia. Cuestionan su calidad y falta de impacto donde, como siempre, está latente la preocupación sobre el rol de la ciencia y la tecnología en el desarrollo y el logro del bienestar para las mayorías.

\section{REFERENCIAS}

KREIMER, Pablo.

Science and society in Latin America: peripheral modernities. New York: Taylor \& Francis. 2019.
LATOUR, Bruno; WOOLGAR, Steve.

Laboratory life: the social construction of scientific facts. Beverly Hills: Sage. 1979.

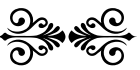

